\title{
Thoracoscopic surgery for tracheal and carinal resection and reconstruction under spontaneous ventilation
}

Long Jiang, MD, PhD, ${ }^{\mathrm{a}}$ Jun Liu, MD, PhD, ${ }^{\mathrm{a}}$ Diego Gonzalez-Rivas, MD, ${ }^{\mathrm{b}}$ Yaron Shargall, MD, Martin Kolb, MD, PhD, ${ }^{\mathrm{d}}$ Wenlong Shao, MD, PhD, ${ }^{\mathrm{a}}$ Qinglong Dong, MD, ${ }^{\mathrm{e}}$ Lixia Liang, $\mathrm{MD},{ }^{\mathrm{e}}$ and Jianxing $\mathrm{He}, \mathrm{MD}, \mathrm{PhD}^{\mathrm{a}}$

\section{ABSTRACT}

Objectives: To describe and assess the techniques of spontaneous-ventilation video-assisted thoracoscopic surgery (SV-VATS) for tracheal/carinal resections and compare the outcomes with the conventional thoracoscopic intubated method.

Methods: From May 2015 to November 2016, some 18 consecutive patients with malignant or benign diseases invading distal trachea and carina who met the criteria for SV were treated by SV-VATS resection. To evaluate the feasibility of this novel technique, they were compared with a control group consisting of 14 consecutive patients with the same diseases who underwent VATS resection using intubated general anesthesia from October 2014 to April 2015. Data were collected with a median follow-up of 10.2 months 75 (range: 1-27).

Results: The SV-VATS group consisted of 4 carinal resections and 14 tracheal resections. In the control group, 2 patients underwent carinal resection and 12 underwent tracheal resection. Median operative time was shorter in the SV-VATS group compared with the intubated group (162.5 minutes vs 260 minutes), as was the median time for tracheal end-to-end anastomosis (22.5 minutes vs 45 minutes) and carinal reconstruction (40 minutes vs 86 minutes). The lowest oxygen saturation during the procedure was $94.2 \% \pm 4.9 \%$ in SV-VATS group and $93.9 \% \pm 4.5 \%$ in the control group. The peak carbon dioxide level at the end of expiration was greater in the SV-VATS group $(47.7 \pm 4.2 \mathrm{~mm} \mathrm{Hg}$ vs $39.1 \pm 5.7 \mathrm{~mm} \mathrm{Hg}$ ). No conversion to tracheal intubation was needed in the SV-VATS group. Postoperative complications occurred in 6 patients in the SVVATS group and 9 in the control group. Patients who underwent SV-VATS had a trend toward shorter postoperative hospital stays $(11.5 \pm 4.3$ days vs $13.2 \pm 6.3$ days). One recurrence (SV-VATS group) and 2 deaths (one in each group) were observed during follow-up.

Conclusions: SV-VATS is a feasible procedure in tracheal and carinal resection and reconstruction in highly selected patients. It can be a valid alternative to conventional intubated VATS for airway surgery. ( $\mathrm{J}$ Thorac Cardiovasc Surg 2018;155:2746-54)

Video-assisted thoracoscopic surgery (VATS) has been reported as feasible and safe in technically demanding complex tracheal and carinal surgery. ${ }^{1-3}$ However, morbidity is not completely eliminated, with potential risks posed

\footnotetext{
From the a Department of Thoracic Surgery, the First Affiliated Hospital of Guangzhou Medical University; Guangzhou Institute of Respiratory Disease \& China State Key Laboratory of Respiratory Disease \& National Clinical Research Center for Respiratory Disease, Guangzhou, China; ${ }^{b}$ Department of Thoracic Surgery, Coruña University Hospital, Coruña, Spain; ' ${ }^{\mathrm{D}}$ epartment of Surgery, Division of Thoracic Surgery, McMaster University/St Joseph's Healthcare Hamilton, Hamilton, Ontario, Canada; ${ }^{\mathrm{d}}$ Department of Medicine, Pathology and Molecular Medicine, McMaster University, Firestone Institute for Respiratory Health, Hamilton, Ontario, Canada; and ${ }^{\mathrm{e}}$ Department of Anesthesiology, the First Affiliated Hospital of Guangzhou Medical University, Guangzhou, China.

Written on behalf of AME Thoracic Surgery Collaborative Group.
}

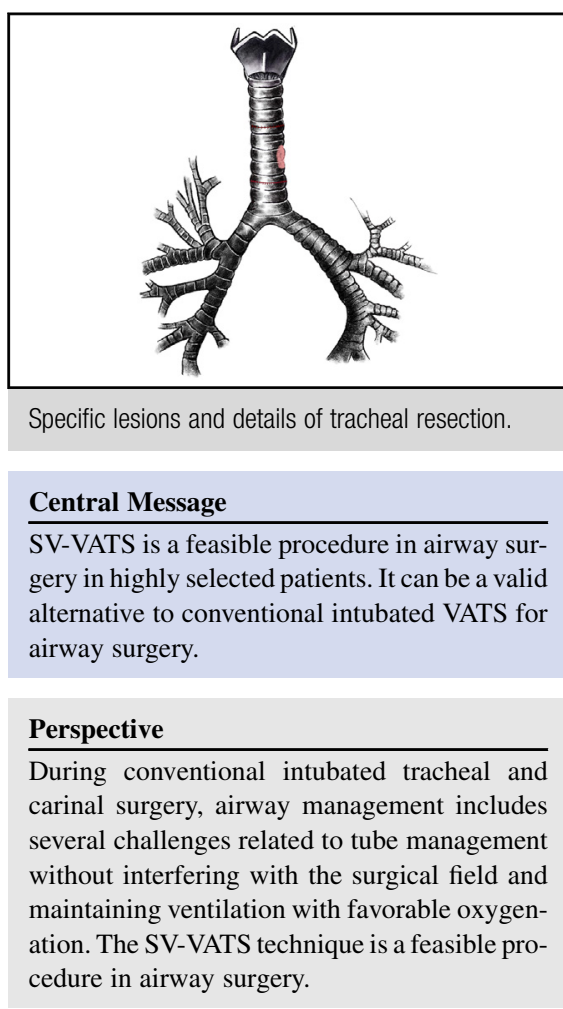

See Editorial Commentary page 2755. by conventional intubation and general anesthesia. Deep anesthesia and intravenous analgesics (primarily opioids) have deleterious systemic side-effects associated with postoperative complications. ${ }^{4,5}$ Mechanical ventilation may 


\section{Abbreviations and Acronyms \\ ASA $=$ American Society of Anesthesiologists \\ BMI = body mass index \\ $\mathrm{CT}=$ computed tomography \\ $\mathrm{EtCO}_{2}=$ end-tidal carbon dioxide \\ SV-VATS $=$ spontaneous-ventilation video-assisted thoracoscopic surgery \\ VATS $=$ video-assisted thoracoscopic surgery}

Scanning this QR code will take

you to a supplemental video for the article.

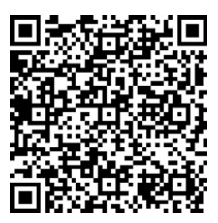

cause airway pressure-induced injury by lung overdistension. ${ }^{6,7}$ Endotracheal intubation can also result in sore throat, mucosal ulceration, and airway injury. ${ }^{8}$

Spontaneous-ventilation video-assisted thoracoscopic surgery (SV-VATS) has recently been extensively investigated and has been reported to reduce the adverse effects of tracheal intubation and general anesthesia. ${ }^{9-15}$ It has been advocated as an alternative to conventional intubated anesthesia for a variety of VATS procedures. ${ }^{12,16,17}$ Our experience mirrored that of previous studies, demonstrating that patients operated under SV-VATS had a shorter postoperative recovery time and were able to eat and mobilize earlier compared with the conventional endotracheal ventilation VATS approach. ${ }^{18,19}$ However, whether the SV-VATS technique can offer benefits for tracheal surgery is unknown. In the present study, we have expanded the SV-VATS application to include tracheal and carinal resections and reconstructions and compared its outcomes with conventional intubated methods.

\section{MATERIAL AND METHODS}

Between October 2014 and November 2016, clinical data for all consecutive patients undergoing VATS tracheal or carinal resection and reconstruction were analyzed. The patients in the control group received combined intravenous anesthesia using a single-lumen 6.5 - $\mathrm{mm}$ endotracheal tube (Well Lead, Inc, Guangzhou, Guangdong, China) for 1-lung ventilation at the start of the procedures. Cross-field ventilation was used during the tracheal and carinal procedures. During the operation, the cross-field endobronchial tube can be introduced through either the operating port or an additional port. ${ }^{1}$ Patients undergoing tracheal or carinal resection using conventional intubation were compared with those undergoing SV-VATS. The study was approved by the First Affiliated Hospital of Guangzhou Medical University Research Ethics Committee.

\section{Preoperative Evaluation}

Cardiac and pulmonary functions were evaluated preoperatively with cardiac 2-dimensional echo, electrocardiogram, and pulmonary function tests. Routine preoperative evaluation to exclude distant metastases included thoracic and abdominal contrast computed tomography (CT) or positron emission tomography-CT scan, magnetic resonance imaging of the brain, and bone scintigraphy. Any ambiguities on the results were resolved by holding a multidisciplinary consultation to decide whether an operation was necessary. During patient evaluation, if bronchoscopic evaluation revealed more than $70 \%$ to $80 \%$ obstruction of the trachea, a wire loop electrocautery was used to resect the majority of the tumor before tracheal resection as described in a previous report. ${ }^{20}$

\section{Indications for SV-VATS Anesthesia}

Patients eligible for SV-VATS fulfilled the following criteria: American Society of Anesthesiologists (ASA) grade of I-II and a body mass index (BMI) <25. Patients with a bleeding disorder, sleep apnea, evidence of pleural adhesions, unfavorable airway features (such as congenital pulmonary airway malformation), or spinal anatomical characteristics were not eligible for this procedure. In addition, preoperative bronchoscopic examination was performed in each case to confirm pathology as well as the extent of tumor involvement evaluated via multiple biopsies. In our center, we consider patients eligible for resection if they have a resectable airway lesion involving no more than $4 \mathrm{~cm}$ of the trachea. Whether the SV-VATS or conventional technique was used was determined by surgeon's preference.

\section{Anesthetic and Surgical Management in SV-VATS Procedures}

Anesthetic considerations. Details of the anesthetic procedure were described in our previous report. ${ }^{21}$ In short, anesthesia was induced with the target-controlled infusion of propofol (target plasma concentration of $2-3 \mu \mathrm{g} / \mathrm{mL}$ ) and sufentanil 0.1 to $0.2 \mu \mathrm{g} / \mathrm{kg}$. Muscle relaxants were not used. Bispectral index monitoring was maintained at 40 to 60 during the operation. The spontaneous respiration rate was 12 to 20/min. During spontaneous ventilation, a gradual and natural collapse of the operative lung occurred, allowing maximal visualization of the lungs after making the incisions. To reduce cough induced by thoracoscopic manipulations, under direct thoracoscopic vision vagus nerve block was performed and $2 \%$ lidocaine was sprayed on the surface of the lung. ${ }^{22}$

Anesthesia was maintained with target-controlled infusion of propofol (target plasma concentration of 1-2 $\mu \mathrm{g} / \mathrm{mL}$ ), dexmedetomidine $0.5-1 \mu \mathrm{g} /$ $\mathrm{kg} / \mathrm{h}$, and remifentanil $0.05 \mu \mathrm{g} / \mathrm{kg} / \mathrm{min}$. Incisions were performed after local application of $1 \%$ lidocaine. Optimally, the intercostal muscle and pleura were infiltrated under direct vision or palpation through the skin incision. The patient's electrocardiogram, heart rate, blood pressure, pulse oxygen saturation, end-tidal carbon dioxide $\left(\mathrm{EtCO}_{2}\right)$, respiratory rate, and bispectral index were continuously monitored. During the procedure, a laryngeal mask was used for oxygen inhalation, with an oxygen flow of 4 to $5 \mathrm{~L} / \mathrm{min}$, keeping oxygen saturation above $95 \%$. Endotracheal ventilation and cross-field ventilation also were prepared as backup in case of an emergency situation, such as hypoxemia, requiring perioperative conversion of the intubation method.

\section{Surgical Techniques}

Surgical preparation for all patients was identical. All patients were positioned in a left lateral decubitus position. Three incisions were made: a 10-mm camera port, at the seventh intercostal space along the right anterior axillary line; a 4-cm main operative port, located at the fourth intercostal space on the right anterolateral chest wall; and a $10-\mathrm{mm}$ port, at the seventh intercostal space along the right posterior axillary line. We used a flexible bronchoscope through the laryngeal mask to identify the proximal and distal extent of the lesion. If lung resection was needed, it was performed followed by lymph node dissection.

The azygous vein was dissected and divided, if needed, via a $35-\mathrm{mm}$ Endo cutter (Ethicon, Inc, Somerville, NJ). The parietal pleura was then opened from this point extending toward the apex, along the lateral side 


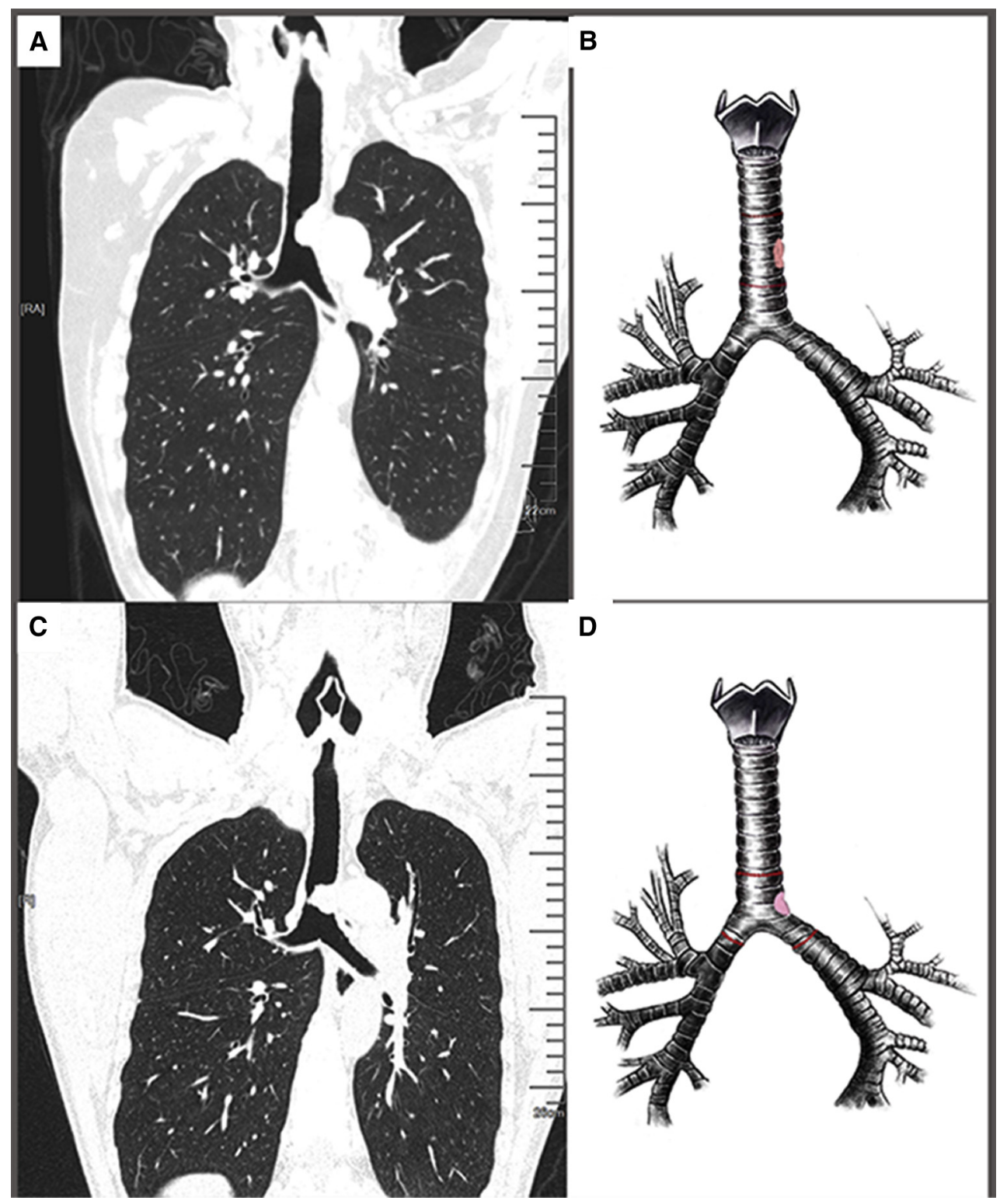

FIGURE 1. Specific lesions and details of tracheal and carinal resection and reconstruction. A and C, Reconstructed computed tomography of the chest; B and $\mathrm{D}$, surgical resection plan.

of the superior vena cava. This maneuver allowed the trachea and proximal bronchus to be mobilized with a combination of blunt dissection and Harmonic Scalpel (Ethicon, Inc). Right paratracheal lymph nodes were also removed to aid with exposure and mobilization of the airway if necessary. Extra attention was taken during this dissection to protect the bronchial arteries and vagus nerve. The right vagus nerve was identified and carefully moved to one side. We sometimes suspended it to the posterior chest wall with 3-0 polypropylene (PROLENE, Ethicon, Inc). A silicon sling was then placed around the trachea and each of the bronchi. Extra 3-0 PROLENE retraction sutures were also placed in each of the airways. This technique allowed retraction and exposure of the airway for further resection and reconstruction.

Preoperative bronchoscopic examination was performed to confirm pathology, as well as the extent of tumor involvement evaluated via multiple biopsies. According to the biopsies, the resection was performed 5 to $10 \mathrm{~mm}$ above and below the tumor margins. If the lesion was malignant, we resected the trachea on the near position of tumor cell-free. Two types of surgical procedures were performed in our study: tracheal resection with end-to-end anastomosis and carinal resection and reconstruction with 2 sets of anastomosis (Figures 1-3). Cervical extension was sometimes changed to a lower degree to allow the trachea to move into the mediastinum before the initiation of anastomosis. Anastomosis was carried out using a continuous 3-0 PROLENE suture, starting from the posterior cartilaginous tissue followed by the membranous section. For carina reconstruction, we performed the resection of the carina first, followed by a total end-to-end anastomosis between the left main bronchus and the trachea, and finally anastomosis of the right main bronchus to the lateral, cartilaginous wall of the trachea. After end-to-end suture of the trachea, we used additional 3-0 PROLENE tension-reduction suture to strengthen and protect the anastomosis. We did not use muscle flaps or other tissues to protect the anastomosis, and we do not perform hilar release. 

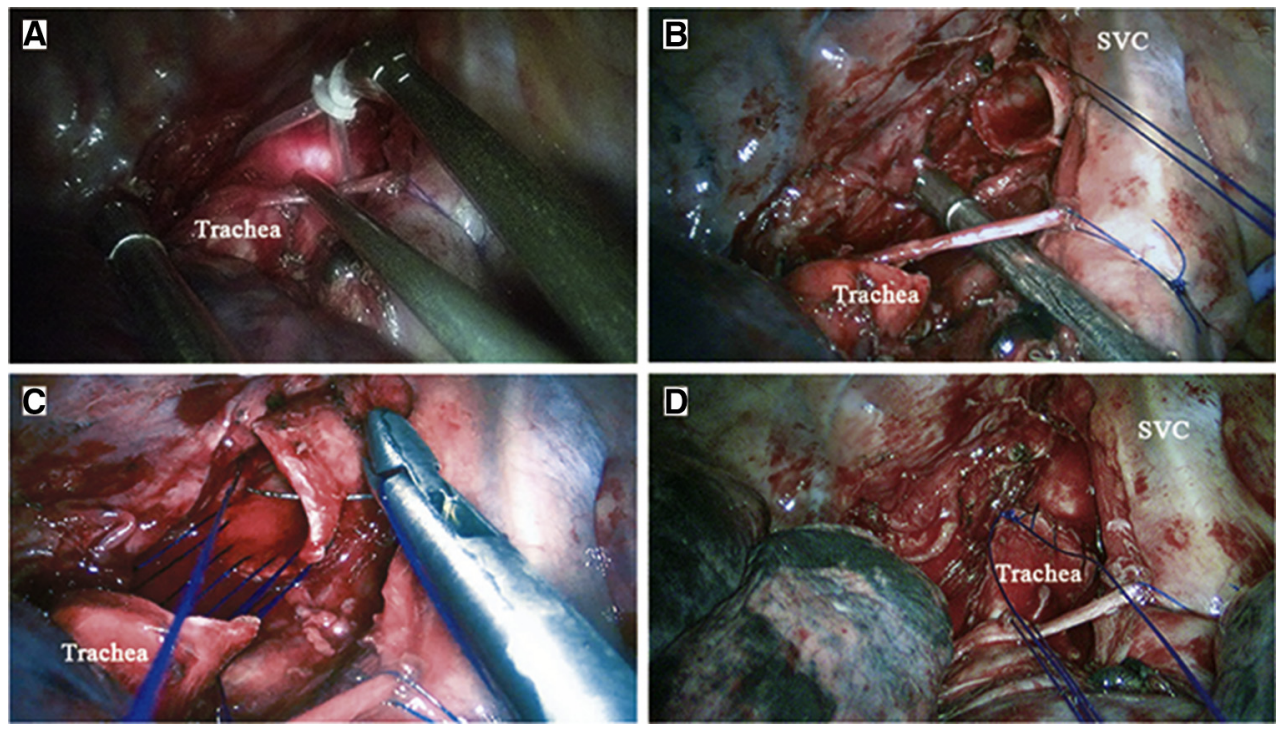

FIGURE 2. Key techniques in tracheal resection and reconstruction. A, Determine the tumor margins under the bronchoscopic view. B, Mobilize the trachea and resect the tumor. C, End-to-end anastomosis of the trachea starting from the distal corner of the posterior tracheal wall. D, End-to-end anastomosis being completed. $S V C$, Superior vena cava.

After completion of the anastomosis, we used a saline solution to test for evidence of air leaks. If any air leak was observed, additional stitches were used to reinforce the suture until intraoperative air leak test was confirmed negative. Only one chest tube is placed at the end of the operation (Video 1).

At the end of the surgery, a bronchoscopy was used to check the integrity of the anastomosis and, if there were concerns with sputum retention, any airway secretion was cleared. On completion of the operation, stitches between the chin and chest or Philadelphia cervical collars were placed to avoid excessive tension in the early postoperative stage.

\section{Postoperative Care in Both Groups}

Patients were transferred to the intensive care unit if necessary according to the intraoperative and anesthesia situations in the operating room and during recovery. Chest radiograph and bedside ultrasound were performed for evaluation on the same day. The voice was accessed by otolaryngologists by using a professional speech and voice analysis system (Voice Disorder Index). Painkillers, such as nonsteroidal anti-inflammatory drugs or a fentanyl patch, were used if necessary. Formal pain assessment for the study was carried out on the morning of postoperative day 1 with the Visual Analog Scale ( 0 is completely pain-free and 10 is hard to tolerate).
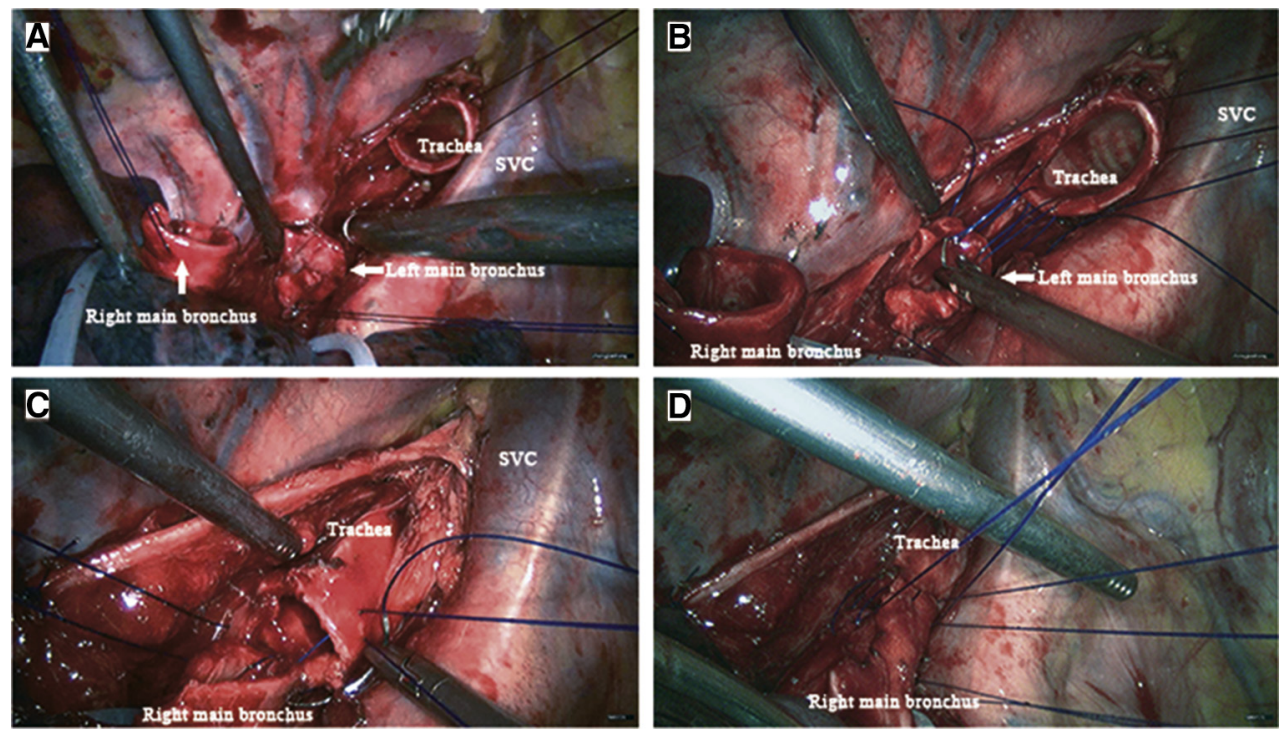

FIGURE 3. Key techniques in carinal resection and reconstruction. A, Mobilize the trachea and bronchus and resect the tumor. B, End-to-end anastomosis of the distal trachea and the left main bronchus starting from the posterior tracheal wall. C, Right main bronchus being implanted into the aperture. D, Carinal reconstruction being completed. $S V C$, Superior vena cava. 


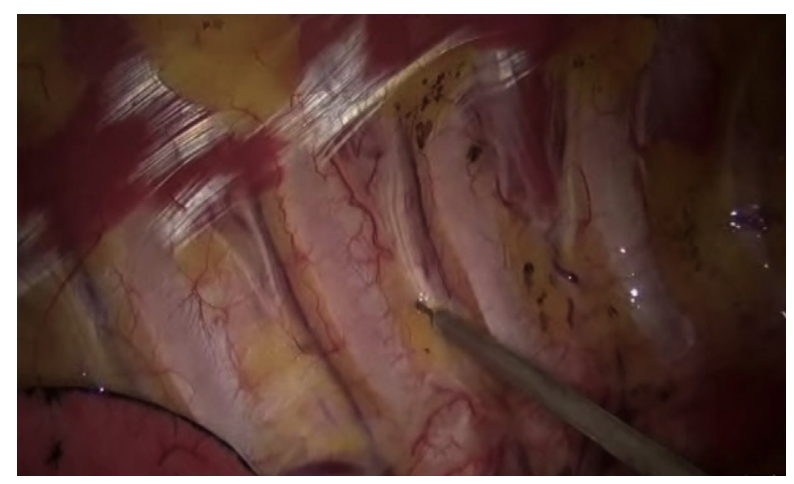

VIDEO 1. The surgical procedure of SV-VATS carina resection and reconstruction. SV-VATS, Spontaneous-ventilation video-assisted thoracoscopic surgery. Video available at: http://www.jtcvsonline.org/article/S00225223(18)30405-7/fulltext.

\section{Statistical Analysis}

Continuous data are presented as mean \pm standard deviation, median and interquartile range, depending on the distribution. The $95 \%$ confidence intervals are also reported. Categorical variables are given as a count and percentage of patients. Some variables were not-normally distributed (surgical duration, time of tracheal end-to-end anastomosis, time of carinal reconstruction, intraoperative blood loss), so median (interquartile range) was summarized. All statistical tests were performed with SPSS 13.0 for Windows (SPSS, Inc, Chicago, Ill).

\section{RESULTS}

Between October 2014 and November 2016, a total of 18 patients underwent SV-VATS tracheal/carinal resection and reconstruction for benign or malignant diseases in our center (trachea: 14; carina: 4) (Group 1, SV-VATS). This group was compared with a group of patients consisting of 14 patients who underwent conventionally intubated VATS procedures (trachea: 12; carina: 2) during the same period of time (Group 2, control group). Age, sex, BMI, comorbidities, pulmonary and cardiac functions, lesion size, distance from vocal cords, bronchoscopic biopsy patch, and pathologic diagnosis did not differ between the 2 groups. However, the ASA status was different between both groups, as there were no grade III patients in the SV-VATS group whereas 4 patients with an ASA grade III were included in the control group (Table 1).

TABLE 1. Clinical characteristics of the patients

\begin{tabular}{|c|c|c|}
\hline Variable & $\begin{array}{l}\text { SV-VATS events, } \\
\quad \mathrm{n}=18\end{array}$ & $\begin{array}{l}\text { Control events, } \\
\quad \mathrm{n}=14\end{array}$ \\
\hline Age, y (median, range) $[95 \% \mathrm{CI}]$ & $49(16-59)[36-51]$ & $36(16-74)[30-52]$ \\
\hline \multicolumn{3}{|l|}{ Sex, \% } \\
\hline Male & $10(56)$ & $10(71)$ \\
\hline Female & $8(44)$ & $4(29)$ \\
\hline Body mass index, $\mathrm{kg} / \mathrm{m}^{2}$, mean $\pm \mathrm{SD}[95 \% \mathrm{CI}]$ & $21.7 \pm 2.1[20.6-22.8]$ & $22.6 \pm 7.7[18-27.2]$ \\
\hline \multicolumn{3}{|l|}{ Comorbidity, \% } \\
\hline Hypertension & $2(11)$ & $2(14)$ \\
\hline Diabetes mellitus & $1(6)$ & $2(14)$ \\
\hline Nonalcoholic fatty liver disease & $2(11)$ & $2(14)$ \\
\hline Cardiovascular disease & 0 & 0 \\
\hline Others & $4(22)$ & $1(7)$ \\
\hline \multicolumn{3}{|l|}{ Pulmonary function texts, $\%$, mean $\pm \mathrm{SD}[95 \% \mathrm{CI}]$} \\
\hline Forced vital capacity & $91.7 \pm 10.4[86.4-97]$ & $91 \pm 14.4[80.2-101.8]$ \\
\hline Forced expiratory volume in $1 \mathrm{~s}$ & $67.7 \pm 27.8[53.5-82]$ & $68.5 \pm 33.4[43.4-93.7]$ \\
\hline Ventricular ejection fraction, $\%$, mean $\pm \mathrm{SD}[95 \% \mathrm{CI}]$ & $73.4 \pm 4.6[70.0-75.4]$ & $70.5 \pm 4.5[67.4-72.9]$ \\
\hline Max length of lesion, $\mathrm{cm}$, mean $\pm \mathrm{SD}$ (range) $[95 \% \mathrm{CI}]$ & $1.9 \pm 0.7(0.7-3.2)[1.5-2.3]$ & $2.1 \pm 0.8(1.1-3.8)[1.6-2.5]$ \\
\hline Distance from vocal cords, $\mathrm{cm}$, mean $\pm \mathrm{SD}$ (range) $[95 \% \mathrm{CI}]$ & $7.4 \pm 0.8(6-8.5)[7.0-7.8]$ & $7.9 \pm 1.5(6-10)[7.0-8.8]$ \\
\hline \multicolumn{3}{|l|}{ ASA status, $\%$} \\
\hline I & $12(67)$ & $3(21)$ \\
\hline II & $6(33)$ & $7(50)$ \\
\hline III & - & $4(29)$ \\
\hline Bronchoscopic biopsy, times, mean \pm SD & $8 \pm 2$ & $7 \pm 3$ \\
\hline \multicolumn{3}{|l|}{ Pathologic diagnosis, $\mathrm{n}(\%)$} \\
\hline Adenoid cystic carcinoma & $5(28)$ & $3(21)$ \\
\hline Squamous-cell carcinoma & $5(28)$ & $2(14)$ \\
\hline Mucoepidermoid carcinoma & $2(11)$ & $1(7)$ \\
\hline Glomangioma & $2(11)$ & $1(7)$ \\
\hline Others & $4(22)$ & $7(50)$ \\
\hline
\end{tabular}

SV-VATS, Spontaneous-ventilation video-assisted thoracoscopic surgery; $C I$, confidence interval; $S D$, standard deviation; ASA, American Society of Anesthesiologists. 
TABLE 2. Operative details

\begin{tabular}{|c|c|c|}
\hline Variable & $\begin{array}{l}\text { SV-VATS group, } \\
\quad \mathbf{n}=\mathbf{1 8}\end{array}$ & $\begin{array}{c}\text { Control group, } \\
\qquad \mathbf{n}=14\end{array}$ \\
\hline Surgical duration, min, median (IQR) $[95 \% \mathrm{CI}]$ & $162.5(75)[141.0-204.3]$ & 260 (126) [193.4-305.7] \\
\hline $\begin{array}{l}\text { Time of tracheal end-to-end anastomosis, min, median (IQR) } \\
{[95 \% \mathrm{CI}]}\end{array}$ & $22.5(20.4)(n=14)[19.3-38.4]$ & $45(28.3)(\mathrm{n}=12)[37.2-65.1]$ \\
\hline Time of carinal reconstruction, min, median (IQR) $[95 \% \mathrm{CI}]$ & $40(14.3)(n=4)[28.3-53.2]$ & $86(-)(n=2)[22.5-149.5]$ \\
\hline Lowest $\mathrm{SpO}_{2}$ during operation, $\%$, mean $\pm \mathrm{SD}$ (range) $[95 \% \mathrm{CI}]$ & $94.2 \pm 4.9(83-100)[91.7-96.7]$ & $93.9 \pm 4.5(85-100)[91.2-96.5]$ \\
\hline Peak $\mathrm{EtCO}_{2}$ during operation, $\mathrm{mm} \mathrm{Hg}$, mean $\pm \mathrm{SD}$ (range) $[95 \% \mathrm{CI}]$ & $47.7 \pm 4.2(41-55)[45.5-49.8]$ & $39.1 \pm 5.7(30-47)[35.6-42.5]$ \\
\hline Conversion to tracheal intubation & 0 & - \\
\hline Intraoperative blood loss, mL, median (IQR) $[95 \% \mathrm{CI}]$ & 25 (30) [24.1-48.2] & $35(82.5)$ [23.3-94.6] \\
\hline Lymph node sample number, median (range) & $11(2-35)(n=11)$ & $14(2-23)(n=11)$ \\
\hline Lymph node involvement (N2) & 2 & 2 \\
\hline Length of excision, $\mathrm{cm}$, mean $\pm \mathrm{SD}$ (range) $[95 \% \mathrm{CI}]$ & $2.5 \pm 1(1.2-4)[2.0-3.0]$ & $2.6 \pm 1.5(1-4)[1.8-3.5]$ \\
\hline Positive surgical margins & 1 & 3 \\
\hline
\end{tabular}

SV-VATS, Spontaneous-ventilation video-assisted thoracoscopic surgery; $I Q R$, interquartile range; $C I$, confidence interval; $S p O_{2}$, pulse oxygen saturation; $S D$, standard deviation; $\mathrm{EtCO}_{2}$, end-tidal carbon dioxide.

\section{Operative and Anesthetic Data}

The same surgical team performed on all these airway surgeries. Patients in the SV-VATS group had shorter median durations of operative time (162.5 minutes vs $260 \mathrm{mi}-$ nutes), tracheal end-to-end anastomosis time (22.5 minutes vs 45 minutes), and carinal reconstruction time (40 minutes vs 86 minutes) compared with the intubated group. The 2 groups had comparable blood loss, numbers of dissected lymph nodes, and length of tracheal excision. Final pathologic results showed positive surgical margins in 4 patients; all were confirmed adenoid cystic carcinoma (SV-VATS: 1 vs control group: 3) (Table 2).

During the procedures, the mean lowest oxygen saturation was $94.2 \% \pm 4.9 \%$ in SV-VATS group and $93.9 \% \pm 4.5 \%$ in the control group. The mean peak $\mathrm{EtCO}_{2}$ in the SV-VATS group was greater than that in the intubated group ( $47.7 \pm 4.2$ vs $39.1 \pm 5.7)$ due to mild hypercapnia under spontaneous ventilation anesthesia. No conversion to tracheal intubation was needed in the SVVATS group.

\section{Postoperative Recovery}

The postoperative Visual Analog Scale scores of both groups were similar (SV-VATS: $2.7 \pm 0.8$ vs control: $2.6 \pm 0.8)$. The median intensive care unit stay was 1 day in the SV-VATS group and 2 days in the intubated group. In addition, patients who underwent SV-VATS had a trend toward shorter postoperative hospital stay ( $11.5 \pm 4.3$ days vs $13.2 \pm 6.3$ days).

Postoperative complications occurred in 6 patients in the SV-VATS group and 9 in the control group (Table 3). In the SV-VATS group, anastomotic stenosis occurred in 1 patient, which was successfully managed with placement of stents. In the intubated group, anastomotic fistula occurred in $1 \mathrm{pa}-$ tient and was repaired by reoperation. There were no cases of perioperative mortality.

\section{Survival and Follow-up}

During a median follow-up time of 10.2 months, the minimal diameter of tracheal anastomotic position on Chest CT 6 months postoperatively was comparable in both groups $(1.8 \pm 0.2 \mathrm{~cm}$ vs $1.6 \pm 0.4 \mathrm{~cm})$.

TABLE 3. Treatment outcomes

\begin{tabular}{|c|c|c|}
\hline Variable & $\begin{array}{c}\text { SV-VATS group, } \\
\mathbf{n}=\mathbf{1 8}\end{array}$ & $\begin{array}{c}\text { Control group, } \\
\quad \mathbf{n}=14\end{array}$ \\
\hline $\begin{array}{c}\text { Postoperative VAS score, } \\
\text { mean } \pm \text { SD }[95 \% \mathrm{CI}]\end{array}$ & $2.7 \pm 0.8[2.4-3.2]$ & $2.6 \pm 0.8[2.2-3.1]$ \\
\hline \multicolumn{3}{|l|}{ Complications, $\mathrm{n}(\%)$} \\
\hline Anastomotic stenosis & $1(6)$ & - \\
\hline Anastomotic fistula & - & $1(7)$ \\
\hline Hemothorax & $1(6)$ & - \\
\hline Pulmonary atelectasis & - & $1(7)$ \\
\hline Pneumonia & $3(17)$ & $5(36)$ \\
\hline Vocal cord paralysis & $1(6)$ & $2(14)$ \\
\hline $\begin{array}{l}\text { Postoperative ICU stay, d, } \\
\text { median (range) }\end{array}$ & $1(0-12)$ & $2(1-7)$ \\
\hline $\begin{array}{l}\text { Postoperative hospital stay, } \\
\text { d, mean } \pm \mathrm{SD}[95 \% \mathrm{CI}]\end{array}$ & $12 \pm 4[9-14]$ & $13 \pm 6[10-17]$ \\
\hline $\begin{array}{l}\text { Minimal diameter of } \\
\text { anastomotic position } \\
\text { postoperatively, } \mathrm{cm}, \\
\text { mean } \pm \mathrm{SD}[95 \% \mathrm{CI}]\end{array}$ & $1.8 \pm 0.2[1.7-1.9]$ & $1.6 \pm 0.4[1.4-1.9]$ \\
\hline Adjuvant therapy & 6 & 3 \\
\hline
\end{tabular}


TABLE 4. Histology and stage of the tumor $(N=17)$

\begin{tabular}{llcc}
\hline & & \multicolumn{2}{c}{ Cases } \\
\cline { 3 - 4 } Pathologic stage & \multicolumn{1}{c}{ Histology } & $\begin{array}{c}\text { SV-VATS } \\
\text { group }\end{array}$ & $\begin{array}{c}\text { Control } \\
\text { group }\end{array}$ \\
\hline $\mathrm{T}_{4} \mathrm{~N}_{0} \mathrm{M}_{0}$ & Squamous carcinoma & 3 & 2 \\
& Adenocarcinoma & 1 & - \\
& Adenoid cystic carcinoma & 5 & 3 \\
& Mucoepidermoid carcinoma & 2 & 1 \\
& Carcinoid & - & 1 \\
& Squamous carcinoma & 2 & 1 \\
\hline $\mathrm{T}_{4} \mathrm{~N}_{2} \mathrm{M}_{0}$ & Small cell carcinoma & - & 1 \\
\hline
\end{tabular}

$S V$-VATS, Spontaneous-ventilation video-assisted thorocoscopic surgery.

For patients with malignant disease, the final results of tumor stage are shown in Table 4. Six patients in the SV-VATS group and 3 in the intubated group received adjuvant chemo- or radiotherapy (Table 3). One recurrence and 2 deaths were observed during the follow-up time. Mortality was $6.2 \%$ during follow-up.

\section{DISCUSSION}

During conventional intubated tracheal and carinal surgery, airway management may present several challenges. Most significantly is the challenge of maintaining ventilation with favorable oxygenation using an endotracheal tube, which can sometimes interfere with the surgical field. ${ }^{23}$ Cross-field ventilation is a universally accepted strategy for conventional intubated VATS for airway surgery. However, this endobronchial tube may obstruct the view of the anastomosis site and may require periodical retraction during anastomosis to improve exposure. Highfrequency jet ventilation via the lumen of the blocker tube was reported to help achieve one-lung ventilation without causing injury to the tumor. However, there have been concerns that the use of high-frequency jet ventilation could contribute to acute respiratory distress syndrome. ${ }^{24}$ Although the SV technique is likely not possible to be performed during thoracotomy, it is a valid option for VATS cases, as demonstrated both in our own experience and recent literature. Since most of our practice, including

TABLE 5. Reasons for conversion to general anesthesia
1. Major bleeding, severe pleural adhesions, large tumors;
2. Severe hypoxemia, hypercapnia, and acidosis;
3. Hemodynamic instability: hypotension, cardiac index decreased, intractable arrhythmias, and right ventricular failure;
4. Persistent cough that creates difficulty or prevents performing surgery;
5. Excessive movement of the diaphragm or mediastinum, causing unsafe surgery;
6. Inability to collapse the lung; and
7. Intraoperative airways injury.

airways resection and reconstruction, is performed thoracoscopically, it allowed us to carry out this comparative study of conventional VATS intubation airways reconstruction with SV-VATS. Our study suggests that the SV-VATS technique facilitates the anesthetic and surgical procedures.

Without the endotracheal tube, the trachea is more flexible, with a wider range of motion during resection and anastomosis. During the spontaneous ventilation anesthetic procedure, we use a laryngeal mask to protect the airway and aid the intubation procedure in the event emergency intubation is required. Avoiding the use of the endotracheal tube gives surgeons the advantage of an unobstructed view of the surgical field. Because of this, the anastomosis and reconstruction were much faster when compared with the intubated procedures, which resulted in an overall reduction of the operative time.

We demonstrated that SV-VATS was feasible without a need for conversion. Although some hypercapnia was noted compared with the control group, especially during the anastomosis phase, in this case, we have found that temporary suspension of operative maneuvers and measures to maintain adequate hemostasis around the trachea will result in the decrease of $\mathrm{EtCO}_{2}$. Our experience has also shown such hypercapnia to be well tolerated without affecting the hemodynamics or surgical procedures. Of note, it has previously been suggested that permissive hypercapnia may, in fact, improve hemodynamics and ventilation/perfusion match and provide protective effects on inflammatory responses. ${ }^{25}$

During the course of this study, we also developed some tips and tricks regarding the technique. Fire within the chest cavity is a well-documented event during airway surgery ${ }^{26}$ that poses dangers to the patient as well as to the operating theater personnel. The improved management of airway fire during airway surgery is based on prevention. We reinforce coordination and communication between the anesthetic and surgical teams, and systematically use suction to decrease the amount of oxygen near the electrocautery. During these procedures, we used a harmonic endocutter to reduce the risk of airway fire after resection of the trachea. Also at this point, the resulting smoke, if using electrocautery, could affect the oxygen supply and/or increase the patient's airway sensitivity. For patients who inhale too deeply or who have a longer remaining membranous portion after initial resection of the trachea that is likely to result in obstruction of the airway during inhalation, a small fine tube such as nasal oxygen catheter can be placed in the distal portion of the trachea. This tube is used to prevent complete closure of the distal trachea and to protect the spontaneous breathing of the patient after the resection and during the beginning of anastomosis.

In our study, the mortality was $6.2 \%$ during the follow-up time of 10.2 months, which is consistent with mortality rates of previous reports, which ranged from $4 \%$ to 
$12.7 \% .^{27,28}$ There were 4 positive margins (SV-VATS: 1 , IVATS: 3), all of which were adenoid cystic carcinoma, although margins were confirmed tumor-free by frozen section intraoperatively. This might be due to the intrinsic property of adenoid cystic carcinoma, which spread most commonly by direct extension, submucosal, or perineural invasion, in transverse and longitudinal planes. Patients who underwent SV-VATS had a trend toward shorter postoperative hospital stays. This consideration is particularly important in China, where primary care at a patient's home town is not widely available. We believe our SVVATS technique allows early discharge without undue worries about patient safety after discharge home.

The promising outcomes of the SV-VATS may partially be the result of careful patient selection, as outlined earlier in the discussion of our methods. Physical condition should also be taken into consideration. None of the patients in our study received neoadjuvant radiochemotherapy because no metastatic disease was found by preoperative evaluation. At the current time, we do not consider neoadjuvant radiochemotherapy in newly diagnosed $\mathrm{N} 2$ patients requiring carinal reconstruction mainly because of its association with anastomosis-related complications and operative mortality. ${ }^{29}$ We assume that strict preoperative patient selection, good preoperative preparation, and improved postoperative care might have contributed to these encouraging results.

To ensure patient safety, some clearly defined protocol for elective or urgent intubation must be determined before the operation. We have listed some reasons for conversion to general anesthesia in Table 5. In addition, intubation in the lateral decubitus position is a technical challenge for anesthesiologists. The anesthesiologist must be skilled in placing a double-lumen tube, laryngeal mask, fibrotic bronchoscopic intubation, video-assisted system management, and endobronchial blocker to securely choose the most appropriate device depending on the patient's airway, the position of the patient, time of completion of the procedure, and the causes that have led to conversion to general anesthesia. ${ }^{30}$ We think continuous and effective communication between surgeons and anesthesiologists is paramount.

As this is a preliminary feasibility study, some limitations should be acknowledged. First, it is retrospective in nature and bias between the study arms cannot be completely excluded. Second, because of the relative infrequency of such complex surgery, the cohort size is small, limiting the power of analysis and conclusions. Third, the selection criteria itself, specifically in regard to BMI, were designed for a Chinese population. We cannot be certain that our findings are necessarily applicable for populations outside China. For Western populations, for example, the BMI inclusion criteria can perhaps be raised to a BMI of $<30$. $^{31}$

In conclusion, in our experience, SV-VATS for tracheal and carinal resections was feasible. The SV-VATS technique offered shorter operative times and potentially faster recovery than the conventional intubated method. Further prospective research is needed to confirm the validity of these results.

\section{Conflict of Interest Statement}

Authors have nothing to disclose with regard to commercial support.

\section{References}

1. Li J, Wang W, Jiang L, Yin W, Liu J, Shao W, et al. Video-assisted thoracic surgery resection and reconstruction of carina and trachea for malignant or benign disease in 12 patients: three centers' experience in China. Ann Thorac Surg. 2016;102:295-303

2. Zhao G, Dong C, Yang M, Du X, Hu X. Totally thoracoscopic tracheoplasty for a squamous cell carcinoma of the mediastinal trachea. Ann Thorac Surg. 2014;98: $1109-11$.

3. Jiao W, Zhu D, Cheng Z, Zhao Y. Thoracoscopic tracheal resection and reconstruction for adenoid cystic carcinoma. Ann Thorac Surg. 2015;99:e15-17.

4. Sessler DI, Sigl JC, Kelley SD, Chamoun NG, Manberg PJ, Saager L, et al. Hospital stay and mortality are increased in patients having a "triple low" of low blood pressure, low bispectral index, and low minimum alveolar concentration of volatile anesthesia. Anesthesiology. 2012;116:1195-203.

5. Hausman MS Jr, Jewell ES, Engoren M. Regional versus general anesthesia in surgical patients with chronic obstructive pulmonary disease: does avoiding general anesthesia reduce the risk of postoperative complications? Anesth Analg. 2015;120:1405-12

6. Gothard J. Lung injury after thoracic surgery and one-lung ventilation. Curr Opin Anaesthesiol. 2006;19:5-10.

7. Della Rocca G, Coccia C. Acute lung injury in thoracic surgery. Curr Opin Anaesthesiol. 2013;26:40-6.

8. Fitzmaurice BG, Brodsky JB. Airway rupture from double-lumen tubes. J Cardiothorac Vasc Anesth. 1999;13:322-9.

9. Chen JS, Cheng YJ, Hung MH, Tseng YD, Chen KC, Lee YC. Nonintubated thoracoscopic lobectomy for lung cancer. Ann Surg. 2011;254:1038-43.

10. Hung MH, Hsu HH, Chen KC, Chan KC, Cheng YJ, Chen JS. Nonintubated thoracoscopic anatomical segmentectomy for lung tumors. Ann Thorac Surg. 2013; 96:1209-15.

11. Wu CY, Chen JS, Lin YS, Tsai TM, Hung MH, Chan KC, et al. Feasibility and safety of nonintubated thoracoscopic lobectomy for geriatric lung cancer patients. Ann Thorac Surg. 2013;95:405-11.

12. Mineo TC, Pompeo E, Mineo D, Tacconi F, Marino M, Sabato AF. Awake nonresectional lung volume reduction surgery. Ann Surg. 2006;243:131-6.

13. Pompeo E, Mineo D, Rogliani P, Sabato AF, Mineo TC. Feasibility and results of awake thoracoscopic resection of solitary pulmonary nodules. Ann Thorac Surg. 2004; 78:1761-8.

14. Tacconi F, Pompeo E, Fabbi E, Mineo TC. Awake video-assisted pleural decortication for empyema thoracis. Eur J Cardiothorac Surg. 2010;37:594-601.

15. Pompeo E, Tacconi F, Mineo D, Mineo TC. The role of awake video-assisted thoracoscopic surgery in spontaneous pneumothorax. J Thorac Cardiovasc Surg. 2007;133:786-90.

16. Chen KC, Cheng YJ, Hung MH, Tseng YD, Chen JS. Nonintubated thoracoscopic lung resection: a 3-year experience with 285 cases in a single institution. J Thorac Dis. 2012;4:347-51.

17. Chen JF, Lin JB, Tu YR, Lin M, Li X, Lai FC, et al. Nonintubated transareolat single-port thoracic sympathicotomy with a needle scope in a series of 85 male patients. Surg Endosc. 2016;30:3447-53.

18. Liu J, Cui F, Li S, Chen H, Shao W, Liang L, et al. Nonintubated video-assisted thoracoscopic surgery under epidural anesthesia compared with conventional anesthetic option: a randomized control study. Surg Innov. 2015;22:123-30.

19. Liu J, Cui F, Pompeo E, Gonzalez-Rivas D, Chen H, Yin W, et al. The impact of non-intubated versus intubated anaesthesia on early outcomes of video-assisted thoracoscopic anatomical resection in non-small-cell lung cancer: a propensity score matching analysis. Eur J Cardiothorac Surg. 2016;50:920-5.

20. Shao W, Shen J, Ying W, He J. Mediastinoscopic tracheal resection and reconstruction under spontaneous-breathing anesthesia. J Thorac Cardiovasc Surg. 2016;151:e105-7.

21. Guo Z, Yin W, Wang W, Zhang J, Zhang X, Peng G, et al. Spontaneous ventilation anaesthesia: total intravenous anaesthesia with local anaesthesia or thoracic 
epidural anaesthesia for thoracoscopic bullectomy. Eur J Cardiothorac Surg. 2016;50:927-32.

22. Li S, Jiang L, Ang KL, Chen H, Dong Q, Yang H, et al. New tubeless videoassisted thoracoscopic surgery for small pulmonary nodules. Eur J Cardiothorac Surg. 2017;51:689-93.

23. Nakanishi R, Yamashita T, Muranaka K, Shinohara K. Thoracoscopic carinal resection and reconstruction in a patient with mucoepidermoid carcinoma. $J$ Thorac Cardiovasc Surg. 2013;145:1134-5.

24. Porhanov VA, Poliakov IS, Selvaschuk AP, Grechishkin AI, Sitnik SD, Nikolaev IF, et al. Indications and results of sleeve carinal resection. Eur J Cardiothorac Surg. 2002;22:685-94.

25. Sinclair SE, Kregenow DA, Lamm WJ, Starr IR, Chi EY, Hlastala MP. Hypercapnic acidosis is protective in an in vivo model of ventilator-induced lung injury. Am J Respir Crit Care Med. 2002;166:403-8.

26. Bowdle TA, Glenn M, Colston H, Eisele D. Fire following use of electrocautery during emergency percutaneous transtracheal ventilation. Anesthesiology. 1987; 66:697-8.

27. Lanuti M, Mathisen DJ. Carinal resection. Thorac Surg Clin. 2004;14:199-209.
28. Block MI, Khitin LM, Sade RM. Ethical process in human research published in thoracic surgery journals. Ann Thorac Surg. 2006;82:6-11; discussion 11-2.

29. de Perrot M, Fadel E, Mercier O, Mussot S, Chapelier A, Dartevelle P. Long-term results after carinal resection for carcinoma: does the benefit warrant the risk? $J$ Thorac Cardiovasc Surg. 2006;131:81-9.

30. Gonzalez-Rivas D, Bonome C, Fieira E, Aymerich H, Fernandez R, Delgado M, et al. Non-intubated video-assisted thoracoscopic lung resections: the future of thoracic surgery? Eur J Cardiothorac Surg. 2016;49:721-31.

31. Gonzalez-Rivas D, Aymerich H, Bonome C, Fieira E. From open operations to nonintubated uniportal video-assisted thoracoscopic lobectomy: minimizing the trauma to the patient. Ann Thorac Surg. 2015;100: 2003-5.

Key Words: carina, resection and reconstruction, spontaneous ventilation, trachea, video-assisted thoracoscopic surgery 